\title{
The Effects of Dry and Wet Grinding Processes on The Salt Quality
}

\author{
Nizar Amir ${ }^{*}$, Makhfud Efendy ${ }^{2}$, Rachmad Hidayat ${ }^{3}$ and Misri Gozan ${ }^{4}$ \\ ${ }^{1}$ Department of Mechanical Engineering, University of Trunojoyo Madura, 69162, Indonesia \\ ${ }^{2}$ Department of Marine Science, University of Trunojoyo Madura, 69162, Indonesia \\ ${ }^{3}$ Department of Industrial Engineering, University of Trunojoyo Madura, 69162, Indonesia \\ ${ }^{4}$ Chemical Engineering Department, Universitas Indonesia, Kampus UI Depok, 16424, Indonesia
}

\begin{abstract}
Studies were conducted on the salt quality, such as $\mathrm{NaCl}$ percent and whiteness achieved by dry and wet grinding methods. Crude solar salt is carefully collected from traditional solar salt ponds to ensure the uniformity of the sample. Several salt processing methods were applied in this research, such as washing, grinding, and dewatering by centrifuge hydro extractor and drying. The effect of reducing salt particle size to 0.6 and $0.25 \mathrm{~mm}$ was also studied. The dry grinding method is conducted before the washing stage, while the wet grinding method is applied after the washing stage. Both dry and wet grinding methods provide high-quality salt products, indicating high $\mathrm{NaCl}$ percent and whiteness. The dry grinding method produces higher $\mathrm{NaCl}$ percent and whiteness than the wet grinding method. However, the wet grinding method was better in water management and equipment durability with loss of salt losses during the washing stage. Finally, both grinding methods have advantages and disadvantages, so for developing the salt processing industry, both methods should be correctly chosen and match product output requirements.
\end{abstract}

Keywords: Grinding Method, Salt Quality, Centrifuge Hydro Extractor

\section{Introduction}

Salt is one of the essential products globally, and it has been widely used in industry [1], [2]. In Indonesia, salt is traditionally harvested from the traditional solar ponds during the dry season and depended on climate conditions [3]. Crude solar salt can not be directly be consumed by industry and need to be processing first. The government and several private companies run the salt processing industry. PN Garam is a government company focused on processing salt and securing salt distribution in Indonesia [4].

The following salt processing is including quality control, grinding, washing, and dewatering. Some specific industry, the salt need to fortified with some additional addictive, such as iron, potassium iodate, folic acid, and tricalcium phosphate [5], [6]. Figure 1 provides an overview of the salt processing methods. Quality control is the initial process to ensure the quality of the crude salt before the processing stage. Reducing the salt particle by the grinding method can improve the salt quality by releasing the trapped impurities inside the salt crystal. In the mineral processing methods, the grinding process can be done in wet and dry conditions [7], [8]. The dry grinding method is applied before the washing stage in salt processing, while the wet grinding method is processed after the washing stage. The advantages of wet grinding over dry grinding in the industry are lower in noise, friction, and energy consumption but higher efficiency [9]-[11].

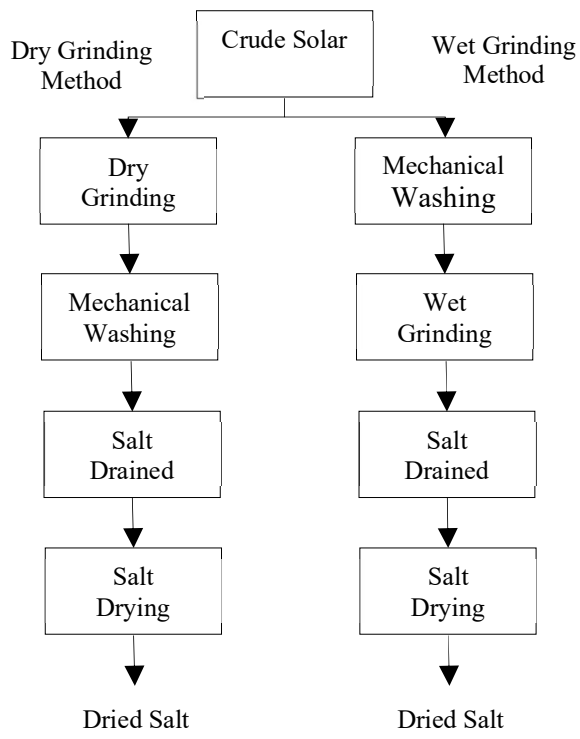

Fig.1. process for Dry and wet grinding methods salt production

\footnotetext{
* Corresponding author : nizar.amir@trunojoyo.ac.id
} 
However, the superfine salt products can be processed only by the dry grinding method [12]. So the grinding method is one of the critical methods and can be adapted to follow the product output requirements. The washing method removes the salt impurities in the crystal surface by washing the salt with saturated brine water [13]. After the washing stage, salt is drained. The drying method continues to reduce water content and produce a high-quality salt product [14]. The saltwater content is accepted by industry is $7 \%, 2,5 \%$, and $0,5 \%$ for human consumption, caustic soda industry, and food industry, respectively.

Producing high-quality salt products with high efficiency in the production cost is crucial to understand the production method and correct selecting the processing step, especially in the salt grinding process. The objective of the present work was to study the effect of dry and wet grinding on salt quality.

\section{Materials and methods}

\subsection{Crude Salt Materials}

A local salt farmer provided the crude solar salt produced in Madura Island's traditional solar salt pond. The crude solar salt uses in this study was classified in first quality. The quality control was conducted by removed the insoluble impurities such as small plastic, wood, leaves, and stone. The salt sample maintained the uniformity of the salt properties, such as water content, $\mathrm{NaCl}$ percent, and whiteness at $12 \%, 90 \% \pm 0.5$, and $72 \% \pm 0.8$, respectively.

\subsection{Processing Methods}

Dry grinding methods: The crude solar salt was ground by the stainless steel hammer mill with a 0.6 and 0.25 $\mathrm{mm}$ sieve. Then, each sample weighed $5000 \mathrm{~g}$ and was washed using $15000 \mathrm{~g}$ saturated brine water for 2 minutes. The salt slurry was collected and poured into a cloth bag and centrifuged in a salt hydroextractor for 10 minutes at $750 \mathrm{rpm}$ to remove the excess water content. The wet salt sample was dried in a hot air dryer at $75^{\circ} \mathrm{C}$ for 30 minutes to obtain a water content of approximately $1,8 \%$ and $1,3 \%$ for 0,6 and $0.25 \mathrm{~mm}$, respectively.

Wet grinding methods: The crude solar salt was washed in saturated brine water for 2 minutes. The wet salts were ground using a disc mill, then poured into a cloth bag and centrifuged in a salt hydroextractor for 10 minutes at $750 \mathrm{rpm}$ to remove the excess water content. The sample was sieved in 0.6 and $0.25 \mathrm{~mm}$ and dried in a hot air dryer at $75^{\circ} \mathrm{C}$ for 30 minutes.

The sample was packed in a plastic container box and stored at ambient temperature before the quality measurement.

\subsection{NaCl Content and Whiteness}

The $\mathrm{NaCl}$ content and whiteness of dried salt samples were measured using commercial equipment (Saltdec
M102, Serial Number SD-201M44). The instrument was calibrated by Additel multifunction calibrator, type ADT221A, with an accuracy level of $99,5 \% \pm 0,4$.

\section{Results and discussion}

Both wet and dry grinding aim to break the salt crystal and released the impurities trapped inside the salt crystal. The reducing salt particle size improved the salt quality by enhancing the $\mathrm{NaCl}$ percent and whiteness due to removing the impurities such as calcium and magnesium [15], [16]. The smaller the salt particle size achieved by the grinding process, the more impurities such as calcium will break from the salt crystal. These impurities will easier to be removed by the washing process. The comparison between wet and dry grinding on $\mathrm{NaCl}$ percent and whiteness is shown in Figures 2 and 3 , respectively, for 0,6 and $0,25 \mathrm{~mm}$.

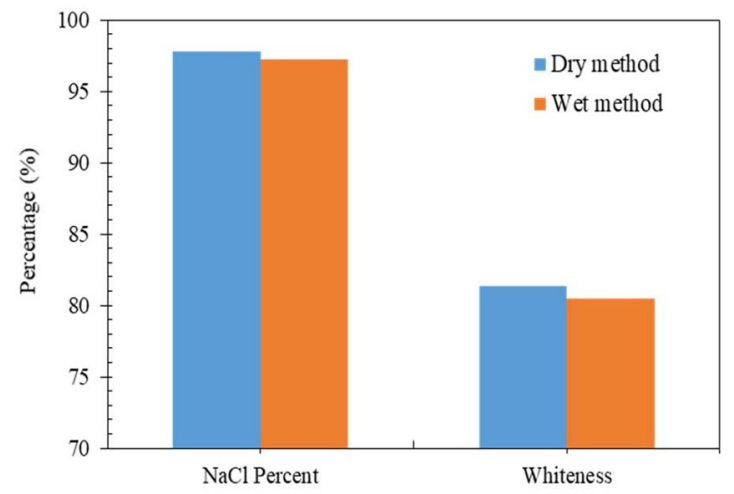

Fig.2. The comparison between dry and wet grinding method on $\mathrm{NaCl}$ percent and whiteness at $0.6 \mathrm{~mm}$ salt particle size

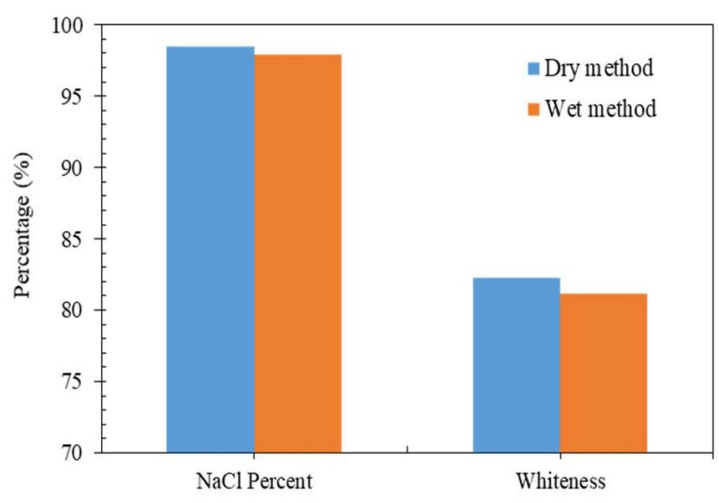

Fig.3. The comparison between dry and wet grinding method on $\mathrm{NaCl}$ percent and whiteness at $0.25 \mathrm{~mm}$ salt particle size

The dry grinding method was done before the salt wash stage. The trapped impurities were perfectly release then removed in the washing stage. The dry grinding method gives more ability to remove the impurities and provided high salt quality. On the contrary, the wet grinding method is begun after the salt washing stage. The crude solar salt was washed in crude 
size. The washing process only removed the impurities in the surface area and produced lower salt quality than dry grinding, as shown in Figure 2 and Figure 3. For example, in the dry grinding method, the $\mathrm{NaCl}$ percent is enhanced from 97,78 percent to 98,47 percent when salt particle size is reduced from $0.6 \mathrm{~mm}$ to $0.25 \mathrm{~mm}$, respectively.

Furthermore, lowering the salt particle size from $0.6 \mathrm{~mm}$ to $0.25 \mathrm{~mm}$ increases the whiteness from 81.34 to 82.26 . Figure 3 shows the comparison between dry and wet grinding methods on salt quality at $0.25 \mathrm{~mm}$ particle size. The dry grinding method has a higher $\mathrm{NaCl}$ percent and whiteness than the wet grinding method. The dry grinding method provides 98.47 percent and 82.26 for $\mathrm{NaCl}$ percent and whiteness, respectively, while the wet grinding method was 97.89 percent and 81.17. However, both grinding methods produce high-quality salt accepted by the caustic soda industry standard followed SNI 0303:2012.

Table 1. Results in washing water after washed stage

\begin{tabular}{|c|c|c|c|c|}
\hline No & $\begin{array}{c}\text { Grinding } \\
\text { method }\end{array}$ & $\begin{array}{c}\text { Particle size } \\
(\mathrm{mm})\end{array}$ & $\begin{array}{c}\text { Weight of } \\
\text { water before } \\
\text { washing }(\mathrm{g})\end{array}$ & $\begin{array}{c}\text { Weight of } \\
\text { water after } \\
\text { washing }(\mathrm{g})\end{array}$ \\
\hline 1 & Wet method & $75-150$ & 150000 & 15570 \\
\hline 2 & Dry method & 0,6 & 150000 & 16210 \\
\hline 3 & Dry method & 0,25 & 150000 & 16710 \\
\hline
\end{tabular}

The dry grinding method negatively impacts the equipment's durability due to high friction, coating formation, and clogging [17], [18]. The wet grinding method provides better efficiency and equipment durability [19], [20]. Using the wet grinding method also improves the salt quantity after the washing stage. Salt in crude particle size $(75-100 \mathrm{~mm})$ is not easy to dissolve in water during the washing stage, and it improves water management, as shown in Table 2. Dry and wet grinding methods have advantages and disadvantages, so for developing the salt processing industry, both methods should be correctly chosen and match product output requirements.

\section{Conclusions}

This study presents an investigation of dry and wet grinding methods on salt quality. The salt quality was measured by $\mathrm{NaCl}$ percent and whiteness. The comparison between dry and wet grinding methods was discussed. Both grinding methods provide high-quality salt accepted by the caustic soda industry. Dry and wet grinding methods can be applied in the salt processing industry because they were suitable for producing salt with $\mathrm{NaCl}$ percent and whiteness more than 97 percent and 80 , respectively. The dry grinding method provides better $\mathrm{NaCl}$ percent and whiteness than the wet grinding method but is poor in salt output quantity and water management after the washing stage due to creating smaller salt particle size and easily dissolved in water. The wet grinding method gives more equipment durability, salt output quantity, and water management.
It is also very beneficial in the salt processing industry due to the salt quality close to the dry grinding method.

\section{References}

[1] E. S. Inguglia, Z. Zhang, B. K. Tiwari, J. P. Kerry, and C. M. Burgess, "Salt reduction strategies in processed meat products - A review," Trends Food Sci. Technol., vol. 59, pp. 70-78, (2017), doi: 10.1016/j.tifs.2016.10.016.

[2] W. Albarracín, I. C. Sánchez, R. Grau, and J. M. Barat, "Salt in food processing; usage and reduction: A review," Int. J. Food Sci. Technol., vol. 46, no. 7, pp. 1329-1336, (2011), doi: $10.1111 / \mathrm{j} .13652621 .2010 .02492 . x$.

[3] M. Kasnir and K. Nisaa, "Feasibility study of salt industry and factor influencing the salt production in Pangkajene Kepulauan," Agrikan J. Agribisnis Perikan., vol. 14, no. 1, pp. 85-89, (2021), doi: 10.29239/j.agrikan.14.1.85-89.

[4] M. Z. Mahasin, Y. Rochwulaningsih, and S. T. Sulistiyono, "The persistence of Chinese monopoly in Indonesia' s salt business and marginalisation of local salt farmers," J. Asia Pacific Econ., vol. 0, no. 0, pp. 1-21, (2021), doi: $10.1080 / 13547860.2021 .1955514$.

[5] S. Chotivichien et al., "Assessment of the contribution of industrially processed foods to salt and iodine intake in Thailand," PLoS One, vol. 16, no. 7 July, pp. 1-15, (2021), DOI: 10.1371/journal.pone.0253590.

[6] O. Modupe, K. Krishnaswamy, and L. L. Diosady, "Technology for Triple Fortification of Salt with Folic Acid, Iron, and Iodine," $J$. Food Sci., vol. 84, no. 9, pp. 2499-2506, (2019), doi: 10.1111/1750-3841.14730.

[7] Y. Umucu, S. Haner, and T. Tunay, "The investigation of effect of wet-dry grinding condition and ball types on kinetic model parameters for Kaolin," Inz. Miner., vol. 16, no. 1, pp. 205-211, (2015), DOI: 10.29227/IM2015-01-28.

[8] S. Cayirli, "Dry grinding of talc in a stirred ball mill," E3S Web Conf., vol. 8, pp. 4-11, (2016), DOI: $10.1051 / \mathrm{e} 3$ sconf/20160801005.

[9] S. Ogonowski, M. Wołosiewicz-Głab, Z. Ogonowski, D. Foszcz, and M. Pawełczyk, "Comparison of wet and dry grinding in electromagnetic mill," Minerals, vol. 8, no. 4, pp. 1-19, (2018), doi: 10.3390/min8040138.

[10] Y. Yang, L. Chen, and Y. Mao, "Different effects of wet and dry grinding on the activation of iron ore tailings," J. Renew. Mater., vol. 9, no. 12 , pp. 2261-2276, (2021), DOI: $10.32604 / \mathrm{jrm} .2021 .015793$

[11] H. Jung, Y. J. Lee, and W. B. Yoon, "Effect of moisture content on the grinding process and powder properties in food: A review," Processes, vol. 6, no. 6, pp. 6-10, (2018), doi: 10.3390/pr6060069.

[12] W. Gao, F. Chen, X. Wang, and Q. Meng, "Recent advances in processing food powders 
by using superfine grinding techniques: A review," Compr. Rev. Food Sci. Food Saf., vol. 19, no. 4, pp. 2222-2255, (2020), DOI: 10.1111/1541-4337.12580.

[13] N. Van Linden, R. Shang, G. Stockinger, B. Heijman, and H. Spanjers, "Separation of natural organic matter and sodium chloride for salt recovery purposes in zero liquid discharge," Water Resour. Ind., vol. 23, no. September 2019, p. 100117, (2020), doi: 10.1016/j.wri.2019.100117.

[14] N. Amir, M. Efendy, Y. J. Yoo, and M. Gozan, "Improved Salt Quality and Reduced Energy Consumption via Hot Air Drying," Int. J. Technol., vol. 12, no. April, pp. 592-601, (2021), doi: 10.14716/ijtech.v12i3.4853.

[15] M. M. Abu-Khader, "Viable engineering options to enhance the $\mathrm{NaCl}$ quality from the Dead Sea in Jordan," J. Clean. Prod., vol. 14, no. 1 , pp. 80-86, (2006), doi: 10.1016/j.jclepro.2004.11.005.

[16] K. Sumada, R. Dewati, and Suprihatin, "Improvement of seawater salt quality by hydroextraction and re-crystallization methods," $J$. Phys. Conf. Ser., vol. 953, no. 1, (2018), DOI: 10.1088/17426596/953/1/012214.

[17] R. Wójcik and K. Nadolny, "The effect of the grinding wheel modification on the state of the workpiece surface layer after internal cylindrical grinding of steel C45," Proc. Inst. Mech. Eng. Part E J. Process Mech. Eng., vol. 231, no. 6, pp. 1162-1173, (2017), doi: 10.1177/0954408916656887.

[18] K. Nadolny and S. Kieraś, "New approach for cooling and lubrication in dry machining on the example of internal cylindrical grinding of bearing rings," Sustain. Mater. Technol., vol. 24, (2020), doi: 10.1016/j.susmat.2020.e00166.

[19] N. Kotake, M. Kuboki, S. Kiya, and Y. Kanda, "Influence of dry and wet grinding conditions on fineness and shape of particle size distribution of product in a ball mill," $A d v$. Powder Technol., vol. 22, no. 1, pp. 86-92, (2011), doi: 10.1016/j.apt.2010.03.015.

[20] X. He et al., "New treatment technology: The use of wet-milling concrete slurry waste to substitute cement," J. Clean. Prod., vol. 242, p. 118347, (2020),

10.1016/j.jclepro.2019.118347. 